\title{
Wind and Solar Energy Curtailment: A Review of International Experience
}

Lori Bird ${ }^{\mathrm{a}}$, Debra Lew ${ }^{\mathrm{b}}$, Michael Milligan ${ }^{\mathrm{a} *}$, E. Maria Carlini ${ }^{\mathrm{c}}$, Ana Estanqueiro ${ }^{\mathrm{d}}$, Damian Flynn ${ }^{\mathrm{e}}$, Emilio GomezLazaro $^{f}$, Hannele Holttinen ${ }^{\mathrm{g}}$, Nickie Menemenlis ${ }^{\mathrm{h}}$, Antje Orths ${ }^{\mathrm{i}}$, Peter Børre Eriksen ${ }^{\mathrm{i}},{ }^{\mathrm{j}}$. Charles Smith ${ }^{\mathrm{j}}$, Lennart Soder $^{\mathrm{k}}$, Poul Sorensen ${ }^{1}$, Argyrios Altiparmakis ${ }^{1},{\text { Yasuda } \text { Yoh }^{\mathrm{m}} \text {, John Miller }}^{\mathrm{a}}$

${ }^{a}$ National Renewable Energy Laboratory, 15013 Denver West Parkway, Golden, CO, USA 80401

${ }^{\mathrm{b}}$ GE Energy, 1 River Road, Schenectady, NY,USA 12345

${ }^{\mathrm{c}}$ Terna Rete Italia, Viale Edgidio Galbani, 70-00156, Rome, Italy

${ }^{\mathrm{d}}$ LNEG, Azinhaga dos Lameiros à Estrada do Paço do Lumiar, 22, 1649-038 Lisboa, Portugal

${ }^{\text {e } U n i v e r s i t y ~ C o l l e g e ~ D u b l i n, ~ B e l f i e l d, ~ D u b l i n ~ 4, ~ I r e l a n d ~}$

${ }^{\mathrm{f}}$ University of Castilla-La Mancha, 02071 Albacete, Spain

${ }^{\mathrm{g}}$ VTT, P.O. Box 1601, FIN-02044 VTT Espoo, Finland

${ }^{\mathrm{h}}$ Hydro Quebec, Varennes, QC J3X 1S1, Quebec, Canada

${ }^{\mathrm{i}}$ Energinet.dk, Tonne Kjaersvej 65, DK-7000 Fredericia, Denmark

${ }^{\mathrm{j}}$ UVIG, P.O. Box 2787, Reston, VA, USA 20195

${ }^{\mathrm{k}}$ KTH, Teknikringen 33, KTH, S-100 44 Stockholm, Sweden

${ }^{1}$ Technical University of Denmark, Anker Engelunds Vej 1 Bygning 101A, 2800 Kgs. Lyngby, Denmark

${ }^{\mathrm{m}}$ Kansai University, 3-3-35 Yamate-cho, Suita, Osaka, Japan

\begin{abstract}
Greater penetrations of variable renewable generation on electric grids have resulted in increased levels of curtailment in recent years. Studies of renewable energy grid integration have found that curtailment levels may grow as the penetration of wind and solar energy generation increases. This paper reviews international experience with curtailment of wind and solar energy on bulk power systems in recent years, with a focus on eleven countries in Europe, North America, and Asia. It examines levels of curtailment, the causes of curtailment, curtailment methods and use of market-based dispatch, as well as operational, institutional, and other changes that are being made to reduce renewable energy curtailment.
\end{abstract}

Keywords-wind; solar; curtailment; transmission congestion

\section{Introduction}

In many regions of the world, penetrations of renewable energy generation, particularly wind and solar energy, have increased substantially as a result of policies, incentives, and declining technology costs. High levels of wind and solar power can be challenging to integrate into electric power systems because of their variability and limits in predictability. In some cases, increased wind and solar penetration levels may drive a system to encounter transmission or operational constraints, forcing the system operator to accept less wind or solar than is available. When high levels of wind and solar generation are planned, infrastructural, operational, or institutional changes to the grid may be necessary. During this transition phase, curtailment may be higher than it is after these changes are made.

There are a variety of reasons for curtailment, including lack of transmission availability and system balancing challenges [1]. System operators often distinguish between the various reasons for curtailment for the purposes of compensating generators and system accounting. We use the term curtailment broadly to refer to the use of less wind or solar power than is potentially available at a given time. Definitions of curtailment can vary, and the availability and tracking of curtailment is limited in some areas.

Transmission congestion, or constraints on the local network, is a common reason for renewable energy curtailment[2]. In cases of where transmission networks are constrained, grid operators may utilize generators with higher marginal-prices instead of less expensive renewable generation, which do not have fuel costs (marginal costs). Lack of transmission access can also cause curtailments. Wind power plants are generally quicker to construct than transmission; therefore, in some instances wind power plants have been built in advance of the necessary transmission infrastructure to transport the energy to load centers. If curtailments are not common, it may be economically efficient to curtail periodically rather than expanding the transmission network.

System balancing issues can be another reason for curtailment. Wind energy, in particular, is often more available at night, when loads are low and thermal units are pushed down against their minimum operating constraints. If thermal plants are either retrofitted or replaced so that the minimum operating constraint is reduced, this type of curtailment may be reduced over time. A related issue is the requirement for downward reserves. If legacy wind and solar plants are unable to provide downward reserves, sufficient downward capability may need to be held on thermal units, raising their operating levels. This should not be an issue with modern wind and solar plants, however.

In the distribution system, curtailment can occur to avoid high penetrations or back-feeding, in which more energy is produced at the feeder level than consumed. High penetrations of solar generation on feeders can lead to voltage control issues due to the

* Corresponding author: Michael Milligan, Michael.Milligan@ nrel.gov, 303-384-6927 National Renewable Energy Laboratory, 15013 Denver West Parkway, Golden, CO 80401 
variability of the resource [3]. Back-feeding can be problematic for the distribution system if protection devices or other infrastructure were not designed, and have not been adapted, for this type of operation.

In some cases, especially on small, isolated grids, limits may be placed on the levels of nonsynchronous generation in order to maintain frequency control and address system stability issues. Modern wind and solar generators interconnect to the grid through the use of power electronics. Conventional synchronous generators provide inertia and often provide governor response. If a contingency event occurs when there is a high penetration of nonsynchronous generation on the system, frequency response might suffer, if non-synchronous generators are not able to provide synthetic inertia and fast frequency controls.

This paper provides an overview of renewable energy curtailment experience internationally. The objective is to understand the magnitude of renewable energy curtailment in various jurisdictions in recent years and how it has been managed. Lessons from these countries may be useful to other areas where additional renewable energy generation is expected in coming years. The following section reviews curtailment levels and causes of curtailment in eleven countries in Europe, North America, and Asia. Subsequent sections provide a broader synthesis and discussion of curtailment methods and mitigation measures or operational changes that are being made to reduce renewable energy curtailment.

\section{Experiences with Curtailment}

\subsection{Canada}

In 2013, approximately 17,500 gigawatt-hours of electricity was generated from wind resources in Canada, which comprised approximately 3.1\% of the nation's overall electricity generation. Hydro Quebec currently has 1,500 MW of installed wind power capacity (5\% energy penetration) and expects to have 3,000 MW of installed capacity (10\% energy penetration) by 2016. TransÉnergie, the transmission system operator (TSO), assumes responsibility for system security. The distributor purchases power from wind developers, estimates the cost of lost energy using wind resource data, and compensates the wind plant operator.

To date, neither voluntary nor mandatory curtailment losses have occurred. However, additional installed wind capacity is planned for the Gaspésie Peninsula and will likely result in curtailment caused by congestion. It may also result in increased voluntary curtailment to ensure system stability.

Given the current projection for 2016 wind penetration levels, Hydro Quebec does not anticipate significant curtailments in the near future. For similar reasons, Hydro Quebec has not yet considered valuing curtailed generation as a source of system operating reserve or strategized how to reduce future losses.

\subsection{China}

In China, installed wind capacity reached $77.16 \mathrm{GW}$ in 2013 with total generation of 142 terawatt-hours (TWh), which represented $73 \%$ of all non-hydropower renewable generation and approximately $2.6 \%$ of the nation's overall electricity generation. Installed wind capacity has grown 56\% annually since 2001 and now represents approximately $6.2 \%$ of China's energy generating capacity, with the vast majority of this capacity situated in northern, northeastern, and northwestern regions of the country. It is anticipated that by the end of 2020 , nearly $200 \mathrm{GW}$ of installed wind capacity will exist, with nearly $85 \%$ of this capacity located at nine large-scale wind power bases located in northern and northwestern portions of China [4,5]. In terms of solar power, China had $18.3 \mathrm{GW}$ of installed solar capacity in 2013 with $11.9 \mathrm{TWh}$ of generation and substantial estimated curtailments exceeding 2013 solar production levels, according to a recent review [6].

Table 1. Curtailment of Wind Power in China

\begin{tabular}{l|cc|cc}
\hline \multicolumn{1}{c|}{ Regions } & \multicolumn{2}{|c|}{$\begin{array}{c}\text { Curtailment } \\
\text { (TWh) }\end{array}$} & \multicolumn{2}{c}{$\begin{array}{c}\text { Percent of Generation } \\
\text { Curtailed }\end{array}$} \\
\hline & $\mathbf{2 0 1 2}$ & $\mathbf{2 0 1 3}$ & $\mathbf{2 0 1 2}$ & $\mathbf{2 0 1 3}$ \\
\hline Jilin & 2.03 & 1.57 & $32.23 \%$ & $21.79 \%$ \\
Gansu & 3.02 & 3.10 & $24.34 \%$ & $20.65 \%$ \\
East Inner Mongolia & 5.24 & 3.40 & $34.30 \%$ & $19.54 \%$ \\
Hebei & 1.77 & 2.80 & $12.48 \%$ & $16.59 \%$ \\
Heilongjiang & 1.05 & 1.15 & $17.40 \%$ & $14.61 \%$ \\
West Inner Mongolia & 6.10 & 2.99 & $26.03 \%$ & $12.17 \%$ \\
Xinjiang & 0.22 & 0.43 & $4.29 \%$ & $5.23 \%$ \\
Liaoning & 1.13 & 0.53 & $12.54 \%$ & $5.00 \%$ \\
Yunnan & 0.17 & 0.17 & $5.98 \%$ & $3.68 \%$ \\
Ningxia & 0.05 & 0.04 & $1.22 \%$ & $0.73 \%$ \\
Shanxi & 0.02 & 0.00 & $0.57 \%$ & $0.00 \%$ \\
\hline
\end{tabular}


In 2013, about 16.23 TWh of wind energy was curtailed throughout China, or about $10.74 \%$ of total wind generation, which was an improvement from the $20.82 \mathrm{TWh}$ of wind curtailed in 2012 [4]. Curtailments have been more severe in some regions with high concentrations of wind generation, as indicated by data in Table 1. In the northern regions of the grid where most of the wind capacity is located, electrical demand is low and insufficient transmission capacity prevents transport to other parts of the grid where demand is greater. In addition, integration of wind and other renewables is hindered by a lack of flexible generating units and a lack of demand-side flexibility. Flexible power pricing mechanisms are not yet in place to enable demand response and effectively influence electricity use for overall system load management.

To address integration and curtailment challenges, China is implementing improved generation scheduling, forecasting, the application of AGC systems, and constructing wind power dispatch systems. In addition, wind-heating pilot projects are underway that use wind to power electric boilers during the heating season and increase local load demand in wind-rich regions [5].

\subsection{Denmark}

At the end of 2014, 4,893 MW of wind power were installed in Denmark (3,622 MW onshore, 1,272 MW offshore), mostly in the Western Danish system. These installations produced 13.1 TWh of electricity (7.9 TWh onshore, 5.2 TWh offshore), which is a $39 \%$ share of Danish electricity consumption (peak load in 2013 was 6,400 MW). Danish Energy Policy targets include a 30\% renewables share of Danish energy consumption in 2020 (heat and electricity), corresponding to $61 \%$ of 2020 electricity consumption sourced from wind.

Wind integration at this penetration level is supported by strong interconnections to neighboring systems and well-functioning international electricity markets. For example, negative price signals are used to encourage wind and other generation to reduce output during periods of over-generation. All wind power is traded in the wholesale markets (day-ahead and intraday power markets), either by production balancing actors or by the Danish TSO. Wind owners are compensated at slightly above the market price. Large offshore wind plant compensation is negotiated during the tendering process.

In 2012, there were 405 hours when wind production exceeded consumption in the Western Danish system. This did not occur in the Eastern Danish system. During these hours, the high-voltage direct current (HVDC) connections between the Danish systems and the hydropower-based systems in Norway and Sweden are useful for sending the wind power where it can be used.

An unusual situation occurred on December 25, 2012: spot market prices in Denmark and Germany were negative because of surplus energy in both systems (Fig. 1). However, German prices were below those in Denmark, causing an import to Denmark while Danish producers' bids had been curtailed to balance demand and supply at the minimum price floor of $-200 €$ per megawatthour (MWh) (Fig. 1). During these hours, consumption was very low. Market actors with heating boilers did not respond to market signals and hence did not activate their boilers. In addition, interconnection capacity to Sweden was reduced to limited export possibilities. Most importantly, wind generation was at high levels in both Denmark and Germany, and total Danish central thermal production was at a low level of $630 \mathrm{MWh} / \mathrm{h}$ to $900 \mathrm{MWh} / \mathrm{h}$ during the critical hours, but electricity was imported from Germany despite negative prices. Among the bids, which were curtailed pro rata, may have been those from wind generation.

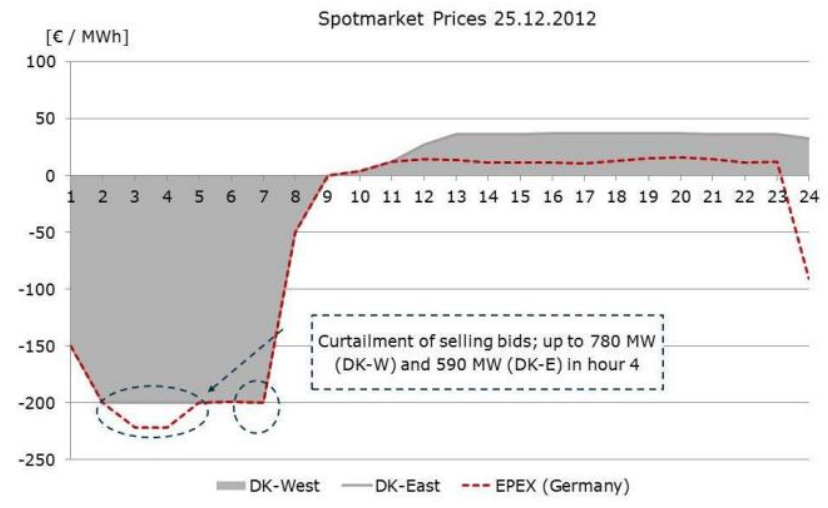

Fig. 1. Spot prices in Denmark and Germany on December 25, 2012 


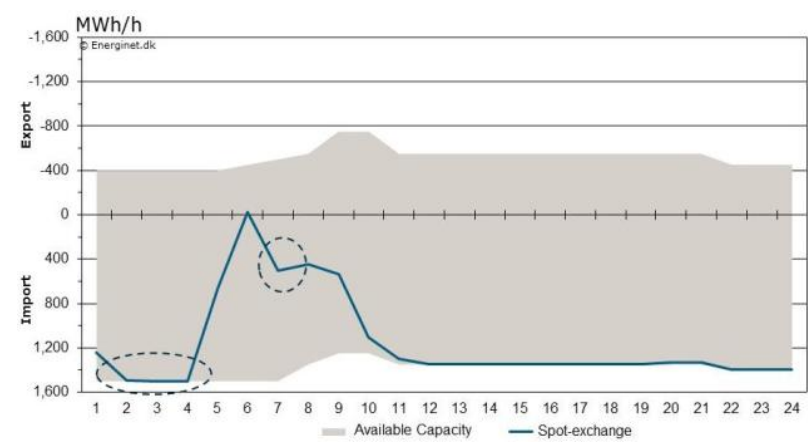

Fig. 2. Exchange between Denmark and Germany on December 25, 2012

To avoid this situation in the future, several improvements have been either recommended or implemented. Market actors should increase their focus on risk for extreme prices and be prepared to act accordingly. Offshore wind power plants are no longer compensated by fixed feed-in tariffs during periods of negative prices. Further, prices in the market in energy overflow situations have been harmonized at both sides of the German/Danish border. The harmonized market price has been settled to $-500 € / \mathrm{MWh}$, This high negative price will increase the probability of the market being balanced by price rather than by curtailment in surplus supply situations.

\subsection{Germany}

According to a report by the German regulator, Budnesnetzagentur (BNetzA) [7], 0.358 TWh of wind energy was unused under the EEG (Renewable Energy Law) scheme, while 50.6 TWh was produced from wind. Thus, the curtailment ratio of wind energy in 2012 can be calculated as $0.71 \%$. Total curtailed renewable energy and its breakdown in Germany in 2012 are shown in Table 2.

Table 2. Renewable curtailment in Germany in 2012 [7]

\begin{tabular}{lcccc} 
& Total & Wind & Solar & Biomass \\
\hline Total generation (TWh) & 138.9 & 50.6 & 26.1 & 34.7 \\
Curtailment (gigawatt-hours & 384.8 & 358.5 & 16.1 & 9.4 \\
$\begin{array}{l}\text { GWh]) } \\
\text { Share in curtailment }\end{array}$ & -- & $93.20 \%$ & $4.20 \%$ & $2.50 \%$ \\
Curtailment/total generation & $0.28 \%$ & $0.71 \%$ & $0.06 \%$ & $0.03 \%$ \\
\hline
\end{tabular}

The BNetzA report [7] also describes that 2 percent of wind curtailment was due to scaling back of installations that were directly connected to TSOs, while the remaining 98 percent was to DSOs.

\subsection{Ireland}

In 2013, Ireland had an installed wind capacity of 2.4 GW (20.5\% of annual electrical demand) and dispatched down $196 \mathrm{GWh}$ (3.2\% of available wind energy). Approximately $44 \%$ of this was caused by system-wide issues, and the remainder was a result of local network constraints [8]. These figures were up notably from the previous year. In 2012, wind production was $16.3 \%$ of annual energy and $110 \mathrm{GWh}$ of wind generation were dispatched down (2.1\% by energy) (Fig. 3). Within Ireland, the distinction between system-wide (curtailment) and local network (constraint) issues for dispatch-down of wind generation is important, a general policy of not remunerating for curtailment, as opposed to constraints, subject to various rules, will be phased in beginning in 2018 .

Typically, curtailment in Ireland occurs during periods of low demand, most often at night from 23:00 to 09:00 in the morning, peaking between 03:00 and 06:00, when minimum generation levels are imposed on conventional generators. Five types of security limits have been defined that could necessitate curtailment, including system stability (synchronous inertia, dynamic and transient stability); operating reserve; voltage control; morning load rise; and, exceedance of the system non-synchronous penetration (SNSP) limit. The SNSP limit, defined as the ratio of non-synchronous generation (wind and HVDC imports) to demand plus HVDC exports, follows from the Facilitation of Renewables studies [9;10], which proposed an upper limit to this ratio (originally $50 \%$, but currently $55 \%$ ) for system stability reasons. 


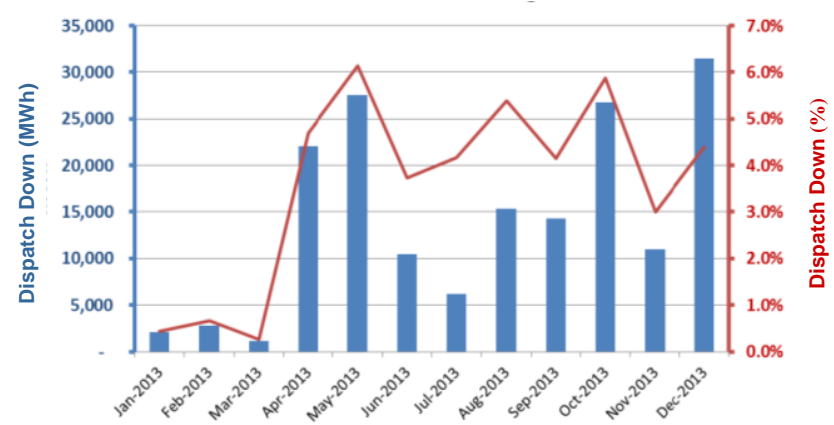

Fig. 3. Dispatch down of wind in Ireland in 2013 [11]

In contrast, local network constraints may occur throughout the day, typically due to network limitations, with the transmission system in the northwestern and southwestern part of the country most affected. Other portions of the transmission network have also experienced local constraints primarily due to maintenance outages.

A number of grid programs are being rolled out to minimize constraint levels. Similarly, the Delivering a Secure Sustainable Electricity System (DS3) Program [11] proposes various forms of plant performance monitoring and new ancillary services, including a synchronous inertial response, fast frequency response, and fast post-fault active power recovery. This will enable the SNSP limit to be raised from $50 \%$ to $75 \%$, which is estimated to reduce the level of curtailment from more than $15 \%$ to approximately $6 \%$. In the short term, a more sophisticated SNSP metric is being considered, which would permit a raised SNSP limit to be applied during periods of high demand (and hence reduced stability concerns), which would enable less wind curtailment [12]. Countertrading by the TSO on one of the HVDC interconnectors to Great Britain has also been in practice since May 2013 as a further measure to facilitate increased wind production while respecting the SNSP limit [13]. As part of grid code requirements, wind turbines have the capability to provide reserve when dispatched down; however, this capability is not currently being utilized.

\subsection{Italy}

In Italy at the end of 2014, the installed capacity of wind and solar PV was about $8.7 \mathrm{GW}$ and $18.7 \mathrm{GW}$, respectively, with total energy penetration at $12.4 \%$ (in southern Italy, the energy penetration was $30.2 \%$.). And, 14.9 terawatt-hours (TWh) of wind generation represented $4.8 \%$ of national electric demand, with most wind power plants (more than 95\%) connected to the transmission grid at the $150-\mathrm{kV}$ voltage level and situated in the south of Italy. Solar PV plants are located more uniformly throughout the country with most of them connected to the distribution grid at the medium- and low-voltage levels (more than 95\% of the PV capacity, corresponding to approximately half a million plants).

Between 2009 and 2013, the growth of renewable electricity standards (RES) in the electricity sector had been supported by three different mechanisms: a feed-in premium scheme ("Conto Energia") for PV installations, a green certificate scheme for all RESs other than PV, and a feed-in tariff scheme for all RESs other than PV with a capacity up to 1.0 MW.

In 2013, support schemes changed in two ways. First, a new support scheme (Conto Termico) was introduced in the heat sector, with a feed-in type of incentive that recovered costs via a levy on gas. Second, the green certificates scheme was replaced by a sliding feed-in premium scheme with an access procedure characterized by the presence of registries and technology-specific reverse auctions. In addition, tax credits incentivized deployment in heat and electricity.

Wind curtailment in Italy occurs sometimes during low-consumption days when there is consistent solar and wind production. Curtailment is undertaken to relieve congestion and maintain adequate reserve margins when no other actions on conventional generators are possible (i.e., conventional power plants are at a minimum generation level). In fact, in these situations, the instantaneous penetration of PV and wind can exceed safe system operation levels in terms of reserve margins, voltage profiles, and dynamic stability issues.

In the past six years, significant grid investments have been made that increased the transmission capacity within and between market zones, which has reduced wind curtailment, as shown in Table 3.

Table 3. Curtailment in Italy, 2009-2014

\begin{tabular}{|c|c|c|c|c|c|c|}
\hline Year & 2009 & 2010 & 2011 & 2012 & 2013 & 2014 \\
\hline Total wind installed (gigawatt-hours, GW) & 4.9 & 5.8 & 6.9 & 8.1 & 8.6 & 8.7 \\
\hline Total wind generation $(\mathrm{GWh})$ & 6,543 & 9,126 & 9,856 & 13,407 & 14,811 & 14,966 \\
\hline Wind Curtailment (GWh) & 700 & 527 & 264 & 166 & 152 & 121 \\
\hline
\end{tabular}




\begin{tabular}{lllllll} 
Curtailment/Total wind generation & $10.70 \%$ & $5.77 \%$ & $2.67 \%$ & $1.24 \%$ & $1.02 \%$ & $0.8 \%$ \\
Total photovoltaic installed (GW) & 1.1 & 3.5 & 12.8 & 16.4 & 18.4 & 18.8 \\
Total photovoltaic generation (GWh) & 676 & 1,874 & 10,668 & 18,637 & 21,228 & 23,299 \\
PV Curtailment $(\mathrm{GWh})$ & 0 & 0 & 0 & 0 & 0 & 0 \\
\hline
\end{tabular}

Very low levels of curtailment (less than $1 \%$ for wind and $0 \%$ for PV in 2014) indicate that Italy has been successful in integrating variable resources up to current levels. However, the design of the Italian intra-day and balancing markets will be optimally adapted to high shares of variable generation, according to an EU target model. Moreover, visibility and controllability of PV systems should be improved further.

The cost of curtailment is borne by the system (included in the tariff) with all the wind projects that are compliant with the grid code (edition 2009) being compensated for the curtailment without any limitation. Only those wind projects that are not perfectly compliant with the grid code are not being compensated for the first 80 hours of curtailments.

In the past, the Italian regulator offered an incentive to the TSO to reduce the amount of curtailment investments for upgrading the network. This was particularly done to accommodate wind power, which is concentrated in southern Italy. PV capacities are more evenly spread throughout the country and have been absorbed with fewer accommodations by the transmission grid.

New investments in battery storage (energy and power intensive) are in progress with 51 MW (35 MW energy intensive in the mainland and $16 \mathrm{MW}$ power intensive in the main islands) currently in operation in southern Italy. This has been done to help increase the flexibility of the overall system and reduce curtailments and local congestion while optimizing spinning reserves with ultra-rapid frequency regulation.

\subsection{Japan}

In Japan at the end of fiscal year 2013, the installed capacity of wind and PV was $2.6 \mathrm{GW}$ and 14.5 GW, respectively, with total energy penetration at approximately $2 \%$. Even after the feed-in tariff (FIT) Act (The Act on Special Measures concerning the Procurement of Renewable Electric Energy by Operators of Electric Utilities, Act No. 108 of 2011) was enacted in July 2012, utilities continue to hold their right to curtail wind and solar without compensation for a maximum of 30 days ( $8 \%$ annual). These curtailment requirements are stipulated in the Ministerial Ordinance for Enforcement of the FIT Act (No. 46 of 2012). Some utilities have required wind developers and owners to install secondary batteries onsite to mitigate wind variability in addition to the 30-day uncompensated curtailment.

Priority dispatch is not given for renewable energy generators in Japan, and it is not described in either the FIT Act or the Ministerial Ordinance. According to the latest grid rule issued by the Electric Power Council of Japan, curtailment of wind and solar generation should be implemented before other measures such as interchanges between utilities, curtailment of other power producers and suppliers (independent generators with mainly conventional combustion plants), or curtailment of baseload generators.

According to the FIT Act, utilities shall publish curtailments and the reasons for them when they curtail renewables due to grid security. So far, utilities have made so such announcements, meaning no curtailment of renewables has occurred in Japan to date. However, several areas with huge renewable potential and small capacity, such as Hokkaido and Kyushu, may experience curtailments because of the rapid growth of PV after enforcement of the FIT Act.

\subsection{Portugal}

At the end of 2014, Portugal had $4.9 \mathrm{GW}$ of wind power capacity installed with annual generation of $12.2 \mathrm{TWh}(24 \%$ energy penetration). Legislation restricts curtailment of renewable energy generation except in the case of technical problems. Despite several instances of excess wind (and other nondispatchable plants) in recent years, the Portuguese TSO has yet to curtail wind as a result of technical problems. For the purpose of this article, excess generation in the Portuguese control area that is transmitted to Spain at zero value is called curtailment.

Excess renewable energy generation occurs on the system in times of low loads and high wind. This is exacerbated by generation from non-dispatchable industrial combined heat and power (CHP) plants that increase the supply of energy during nighttime periods of low demand.

Portugal typically manages high-penetration periods by controlling production from run-of-river hydropower plants, exporting excess power to the Spanish energy market and halting the import of electricity from France through Spain. Portugal has two dispatch centers that enable the monitoring, control, and curtailment of a large fraction of wind generation during high-supply/lowdemand periods $[14,15]$.

The Portuguese FIT legislation requires wind producers be compensated only for losses that exceed 50 hours at full capacity, the value of which is calculated at the tariff payment level. Because of the economic burden introduced by these situations and 
significant installed wind power capacity, new permits for connection of wind power plants to the transmission system have been halted until 2020, the only exception being one 75-MW offshore installation.

The Portuguese regulator is currently examining the practice of halting electricity imports during periods of excess electricity generation and has made an initial recommendation that this procedure be replaced with countertrading.

\subsection{Spain}

At the end of 2013, Spain had 22.9 GW of wind power capacity installed, which generated 54 TWh of electricity $(21.2 \%$ energy penetration). Red Eléctrica de España (REE) is the Spanish system operator that manages the nation's distribution and transmission system. In Spain, wind curtailment typically occurs when demand is low and wind production is high. Wind energy curtailments are guided by REE operational procedures 3.2 and 3.7 [16]. According to market procedures, curtailments can be classified as programmed or real-time. Programmed curtailments are set before the day-ahead market is closed (Basic Operation Programme, PDBF), whereas real-time curtailments are obtained from the intra-day markets. The former is not economically compensated, and the latter is partially compensated as a function of daily market price [17].

In the case of real time curtailments, wind generation set-points are computed and delivered (using the Control Centre of Renewable Energies, or CECRE) with maximum wind nodal production, and wind farms affected must adapt their production to the given set-point within 15 minutes. CECRE is an operating unit within the Power Control Center (CECOEL) that is connected to $98.6 \%$ of installed wind power capacity, while the remaining wind power (1.4\%) is estimated [17].

Table 4 shows the wind energy curtailments in Spain from 2008 to 2013. In 2008, wind energy curtailments due to voltage dip stability were $48 \mathrm{GWh}$. Since 2009, this variability has not been an issue as $95 \%$ of wind power in Spain has been equipped with fault ride-through capabilities. Balancing issues between wind generation and load has been the main issue in the years where wind energy curtailments were large (2010, 2012, and 2013). Inadequate transmission and distribution system capacity were the main issues in other years $(2008,2009$, and 2011). From 2010 to 2013, the majority of curtailments were real-time $(94 \%, 95.3 \%, 75.2 \%$, and $81.7 \%$ respectively). Curtailments in 2013 were related to the large amount of wind energy generation in that year $(12.89 \%$ over 2012), when Spain ranked first among European countries in terms of wind energy generation with $54.3 \mathrm{TWh}$. Indeed, due to the technical constraints in the first quarter of the year, wind energy curtailments reached record levels in 2013 compared to the previous five years, with an economic impact of around $85 \mathrm{M} €$, according to the Spanish Wind Energy Association.

Table 4. Wind energy curtailment in Spain, $2008-2013$

\begin{tabular}{|c|c|c|c|c|c|c|}
\hline Year & 2008 & 2009 & 2010 & 2011 & 2012 & 2013 \\
\hline Total wind generation (GWh) & 31,777 & 36,991 & 43,692 & 42,160 & 48,126 & 54,338 \\
\hline Wind generation/total generation & $11.37 \%$ & $13.79 \%$ & $15.8 \%$ & $15.56 \%$ & $18 \%$ & $21.2 \%$ \\
\hline Wind curtailment (GWh) & 108.0 & 69.9 & 315.2 & 73.3 & 121.1 & 1166.0 \\
\hline Curtailment/total wind generation & $0.34 \%$ & $0.19 \%$ & $0.72 \%$ & $0.17 \%$ & $0.25 \%$ & $2.14 \%$ \\
\hline
\end{tabular}

In the Spanish power system, energy storage facilities and flexible combined cycle gas turbines are the key technologies to manage wind variability, taking into account its weak interconnection with the rest of Europe. In [17], several wind power curtailment scenarios are described and analyzed based on real measurements performed over the Spanish electrical system. On the other hand, other relevant aspects related to wind energy curtailment were due to an over-response to the curtailment value, as under certain conditions, some events produce severe deviations from TSO set-points. In [18], some examples are presented, taking into account that these kinds of events may threaten power system operations. From an economic point of view, reserves are being used for balancing, which is producing increased costs.

Future policies to mitigate renewable energy curtailment include providing wind power plant managers with production setpoints, which will be developed by the Control Centre of Renewable Energy. Installing new pumped hydropower storage systems and establishing international transmission interconnections represent additional strategies Spain is exploring to balance significant fluctuations in wind power production. The country may also look to demand-side management, such as smart grid technologies, to improve the supply-demand balance. Valuing curtailed generation as a source of operating reserves has not yet been considered.

\subsection{Sweden}

In Sweden, $4.4 \mathrm{GW}$ of wind capacity were installed in 2013 generating $9.9 \mathrm{TWh}$ and representing $7 \%$ of national electrical demand. The only curtailments that are currently performed are those caused by grid limitations. If grid reinforcements are needed when a wind power plant is installed, the wind power plant owner has to pay for them. The Swedish TSO may curtail wind power plants (e.g., in a situation in which a wind power plant is interconnected before needed grid reinforcements have been completed and a line outage occurs). A signal is sent directly to the wind power plant controller to decrease the output. 
A wind plant in the Jönköping Energi distribution system operator (DSO) has an installed capacity of 29.3 MW but because of possible voltage problems, the wind plant owner has agreed to reduce the infeed to $26 \mathrm{MW}$. This limitation is implemented within the plant. The alternative was for the wind plant owner to pay to strengthen the grid, but analysis of how often the wind plant would produce more than $26 \mathrm{MW}$ showed this was not economically viable. This formally means that the plant is sometimes curtailed up to $3.3 \mathrm{MW}$. The agreement also stipulates that the DSO can decrease the output even below $26 \mathrm{MW}$ if there are voltage problems in the grid. However, this has not been needed since commissioning in 2010[19].

\subsection{United States}

The United States has many balancing areas, which may have their own curtailment practices. In the areas with the most wind energy, curtailment has generally declined in recent years, even as the amount of wind energy has increased as a result of new transmission additions and changes to operational practices. In most regions, curtailment has generally been less than $4 \%$ of wind generation [20]. Some key balancing areas where curtailment has been substantial in certain cases include the Bonneville Power Administration (BPA) balancing area, the Electric Reliability Council of Texas (ERCOT), the Southwest Power Pool (SPP), and Hawaii, which has struggled primarily with excess wind at low-load periods and minimum generation requirements. Both the Midcontinent Independent System Operator (MISO) and the ERCOT have recently implemented market-based solutions and have seen reductions in curtailment levels.

BPA had approximately 4,500 MW of wind and a peak demand of 11,500 MW in its balancing area in 2013, although some wind resources have shifted out of the balancing area recently. Significant wind capacity was added between 2008 and 2012 , with annual additions of about $850 \mathrm{MW}$. There are two types of curtailments that are implemented: curtailments caused by exhaustion of balancing reserves and those that result from seasonal hydropower oversupply. Curtailment events resulting from the exhaustion of balancing reserves exceeded 45 events per month in the spring of 2012 but subsequently fell to $10-15$ events per month. Curtailments resulting from hydropower oversupplies totaled 97 GWh in 2011 and 50 GWh in 2012 then fell to zero in 2013 [20]. Curtailments have been attributed to a lack of system flexibility and balancing challenges, which is caused, in part, by environmental constraints on hydropower units. BPA has been modifying its curtailment protocols and implementing or exploring measures to help reduce the amount of curtailment, including faster scheduling, better use of forecasts, and improved methods of committing and de-committing reserves.

ERCOT shifted from a zonal congestion market with 15-minute dispatch to a nodal market with 5-minute dispatch in December 2010. In addition, new transmission was added, which helped reduce curtailment levels from $17 \%$ in 2009 to $8 \%$ and $9 \%$ in 2010 and $2011,4 \%$ in 2012 , and $1.6 \%$ in 2013 [21].

In the SPP, lack of transmission access has been the primary cause of curtailment. Installed wind capacity has grown rapidlyessentially doubling in 2012 - and has come online ahead of planned transmission. Approximately 7.8 GW of wind are in the system, which has a peak demand of $54 \mathrm{GW}$. Some wind generators have reported substantial curtailments. The use of manual processes to implement curtailments has exacerbated the impacts. Transmission lines scheduled for completion in 2015 should help alleviate curtailment in the future. In the meantime, SPP has held stakeholder processes to improve and increase transparency of its curtailment practices, and it is moving toward an automated, market-based approach [20].

MISO, which has more than $12 \mathrm{GW}$ of wind capacity and a peak demand of $98 \mathrm{GW}$, implemented the Dispatchable Intermittent Resource (DIR) protocol in mid-2011, which includes wind generators in 5-minute dispatch. As a result, manual curtailments have decreased substantially. Prior to the introduction of the DIR program, manual curtailments were used more than 1,000 times annually in 2009 and 2010. Of wind generators not participating in the DIR program, curtailment levels have fallen to $0.2 \%$ of wind generation [22][20]. Similar programs are in place at PJM and the New York Independent System Operator (NYISO).

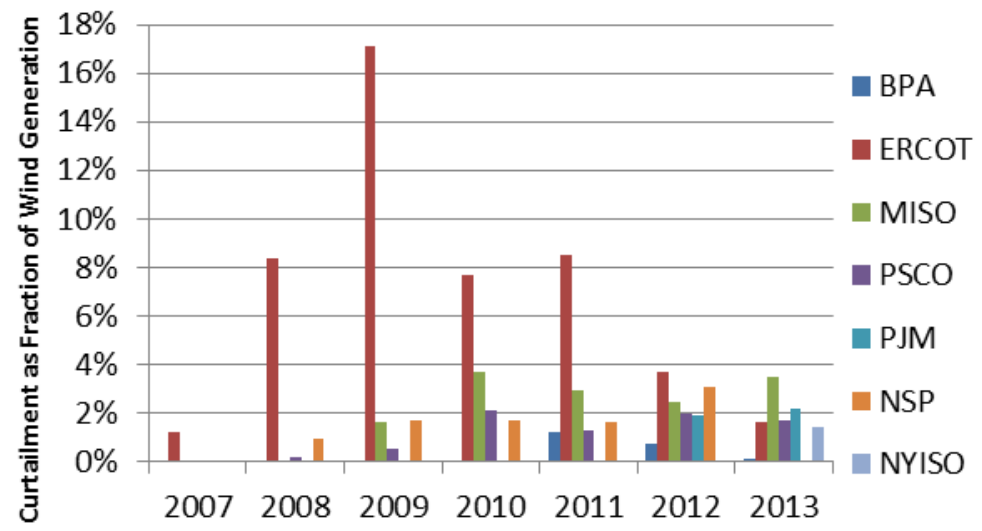

Fig. 4. Curtailment levels by region, 2007-2013 


\subsection{Summary Data}

Table 5 compares 2013 curtailment data for the countries reviewed above (statistics for Germany are for 2012). Across the countries, the penetration of wind energy in the electric sector varies widely, ranging from $1 \%$ to about $30 \%$ of electricity generation. Wind curtailment, where reported, typically ranged from about $1 \%$ to $3 \%$ of wind generation levels, with curtailment levels in China exceeding 10\%. Curtailment levels can vary considerably across balancing areas within particular countries, as discussed above in greater detail for China and the U.S. in particular.

Table 5. 2013 wind generation and curtailment data by country

\begin{tabular}{|c|c|c|c|c|c|c|c|c|c|c|c|}
\hline COUNTRY & Canada & China & Denmark & $\begin{array}{l}\text { Germany } \\
(2012)\end{array}$ & Ireland & Italy & Japan & Portugal & Spain & Sweden & $\begin{array}{l}\text { United } \\
\text { States }\end{array}$ \\
\hline $\begin{array}{l}\text { Electricity Generation } \\
(\mathrm{TWh})^{*}\end{array}$ & 560 & 5,372 & 35 & 577 & 26 & 290 & 950 & 52 & 284 & 153 & 4,066 \\
\hline Wind Generation (GWh) & 17,500 & 142,000 & 11,100 & 50,600 & 5,872 & 14,811 & 4,000 & 11,900 & 54,338 & 9,900 & 167,840 \\
\hline $\begin{array}{l}\text { Wind/Electricity } \\
\text { Generation }\end{array}$ & $3.1 \%$ & $2.6 \%$ & $31.9 \%$ & $9.8 \%$ & $22.5 \%$ & $5.1 \%$ & $0.4 \%$ & $23.0 \%$ & $19.2 \%$ & $6.5 \%$ & $4.1 \%$ \\
\hline Wind Curtailment (GWh) & - & 16,230 & - & 358 & 196 & 152 & - & - & 1,166 & - & - \\
\hline $\begin{array}{l}\text { Wind } \\
\text { Curtailment/Generation }\end{array}$ & - & $11 \% * *$ & - & $0.7 \%$ & $3 \%$ & $1 \%$ & - & - & $2 \%$ & - & $1-3 \% * *$ \\
\hline
\end{tabular}

*Electricity generation statistics were sourced from national/regional resources for each country. Canadian energy generation values and wind generation data were sourced from the IEA Wind 2013 Annual Report [23]. European countries, including Denmark, Ireland, Italy, Portugal, Spain, and Sweden were sourced from total gross electricity generation statistics provided by Eurostat [24]. China electricity generation was sourced from the China Electricity Council [25]. Germany electricity generation was sourced from a 2013 monitoring report from Bundesnetzagentur [7]. Electricity generation information for Japan [26] and the United States [27] was sourced from the U.S. Energy Information Administration.

*** Curtailment levels vary across individual balancing areas.

\section{Curtailment Methods}

The approaches to how wind and solar energy are curtailed vary, ranging from manual to automated methods. And, there is emerging interest in performing curtailment as part of the market function. The advantage to a market-based approach is that economic signals regarding the cost-effectiveness of alternative curtailments (dispatch-down) are transparent. If all market participants, including wind power plants, participate, the solution will be economically efficient. Automated market-based approaches can also be more efficient than manual curtailment processes, and they can reduce the amount of overall curtailment. However, there is typically no compensation for this type of curtailment. Methods of compensation for curtailment are changing in many regions and remain key issues of importance to wind generators and off-takers [28]. This section reviews examples of curtailment methods and how they are evolving to reduce overall curtailments and increase the efficiency of operations.

In the United States, system operators including MISO, ERCOT, PJM, and NYISO use market-based approaches. When no market mechanism exists or is available for curtailment, a system operator must typically decide in real time which plant or plants to curtail. The absence of price signals in such cases will likely result in an economically inefficient outcome. SPP and BPA are examples of U.S. regions that use manual curtailment, although SPP is transitioning to more automated approaches. For example, in 2010, wind was being increasingly curtailed in MISO via manual phone calls from operators. To allow wind to participate in the real-time market like other types of generation, the DIR program was developed. Under the program, MISO obtains a wind forecast for each plant for each five-minute interval that sets the maximum for that plant in that time interval. Wind is part of the cooptimized five-minute market dispatch. This allows wind to set price and to choose not to generate if prices are severely negative.

To address balancing-related events, first experience on using curtailed plants for up or down regulation is emerging. An example is the vertically integrated utility of Xcel/Public Service of Colorado (PSCO), which needs to balance its own load with its own generators (mostly thermal) and long-term contracts with wind power plant owners. At night, when winds are high and loads are low, PSCO runs its thermal units down to minimum generation levels and still needs to curtail wind at times to balance the load. In fact, PSCO has gone a step further, and when wind is curtailed, it uses wind to provide regulating reserves.

In Ireland, a distinction is made between constraints (which are resolved by reducing the output of particular units) and curtailment (which is resolved by reducing the output of some or all units). Constraints are normally applied first and are followed by curtailment, if both are required simultaneously [29]. Curtailment and constraint instructions are administered based on the active power control set-point of each unit. When a dispatch-down instruction is required, first priority is given to non-controllable wind plants (by opening relevant circuit breakers), then controllable wind plants, followed by wind plants that are still in a commissioning phase.

\section{Mitigation Options}


Reducing curtailment often involves increasing the flexibility of the system. Methods of increasing system flexibility include physical additions to the system (e.g., storage), grid capacity, institutional changes (e.g., access to new markets), or operational changes, such as improved forecasting and economic dispatch [30,31]. The use of storage technologies, including compressed air energy storage, and pumped storage, and demand response also hold potential for mitigating curtailment and are being evaluated in various regions [32,33,34,35], Other methods of reducing curtailment (e.g., dynamic topology switching) are being explored, and current research is examining the reductions of system losses and curtailment through intelligent switching or reconfiguration of the transmission network. Applying algorithms for the PJM region with projected wind generation data showed reductions of a few percentage points in curtailment levels [36]. This section reviews examples of measures that jurisdictions have implemented to reduce curtailments.

Portugal has a high penetration of wind energy (24\% in 2014), with limited interconnections to other regions (up to 2,250 MW to Spain) [37]. Other system constraints include run-of-river hydropower and significant CHP plants. To reduce wind curtailment, the Portuguese grid operator uses pumped hydropower and the intertie to Spain. On May 15, 2011, at 06:45, wind penetration reached $81 \%$ of load (Fig. 5). At that time, most of the hydropower generation was shut down, with a few plants remaining online to provide balancing services for the system. The pumped-hydropower storage facilities were pumping at full output. One thermal plant remained in operation, and its output was reduced by 25\% near 04:00 and its operations closely coordinated with the hydropower units. In addition, the system began exporting electricity to France through Spain, rather than importing power.

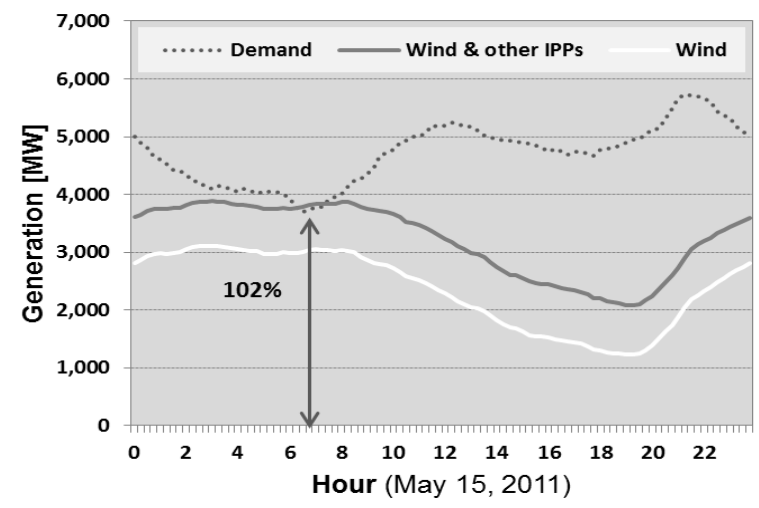

Fig. 5. Portuguese load and generation profiles for May 15, 2011 [37]

In the United States, PSCO has examined high wind scenarios and the trade-offs between cycling coal units and curtailing wind generation (2-GW to 3-GW) [38]. The utility conducted a detailed analysis of the cost of cycling coal units to understand the costs of starts, shallow ramps (to economic minimum generation levels), and deep ramps (to emergency minimum generation levels). Based on the study, PSCO found that shutting down a coal unit during low-load periods, such as at night, was uneconomic. The utility then examined the differences in cycling costs for deep ramps versus shallow ramps with wind curtailment. Costs were found to be similar with either mode of operation.

In Ireland, a specific ranking order is when priority dispatch generation must be dispatched down [39]. The order has been defined to preserve the principle of least-cost dispatch. The TSO may perform countertrades on HVDC interconnectors after gate closure, followed by set-point reductions for peat plant, high-efficiency CHP, biomass, and hydropower generation, and finally wind generation. The output of the peat and CHP units is reduced to their minimum stable generation levels rather than decommitted, as such units represent the major source of negative reserves for the system.

The European Union's Twenties project has examined market scenarios for 2020 and 2030 in Northern Europe, covering countries with plans for significant offshore wind power development: United Kingdom, France, Germany, Belgium, Netherlands, Denmark, Norway, Sweden, Finland, and Poland. The project found that large-scale offshore wind development could increase wind curtailment, mainly due to increased wind generation but also the additional variability from offshore wind plants that are concentrated in geographic region. Market simulations show that wind curtailment is expected to increase from $0.4 \mathrm{TWh}$ in 2020 to 9.3 TWh in 2030 [40].

The Twenties project also examined mitigation options for curtailment of wind generation. One involved introducing virtual power plants - aggregations of distributed generation and demand response that replace conventional generators-in Denmark in 2030. This option was found to reduce wind power curtailment by $0.18 \mathrm{TWh}$ [38]. While this reduction is marginal compared with the 9.3-TWh of curtailment in Northern Europe, consumption in Denmark is only $2.2 \%$ of the consumption in the region, so the effect of virtual power plants could be significant. Another option is the expansion of hydropower and transmission capacity, which 
was found to reduce wind power curtailment by $1.5 \mathrm{TWh}$ [41]. This result confirms that the flexibility of hydropower can significantly mitigate wind power curtailment. Finally, the Twenties project also demonstrated the use of dynamic line rating (DLR) technology for increasing transmission capacity without building additional lines. The study found that a reported $10 \%$ to $15 \%$ increase in transmission capacity using DLR would mean a significant reduction of wind curtailment [42].

\section{Conclusions}

This paper has reviewed renewable energy curtailment experience across eleven countries to illuminate the breadth of experience and methods that have been effectively employed to manage curtailment levels. A variety of factors, such as the generation mix, market structure, operating rules, and transmission grid, affect the operation of renewable energy generators, and hence the potential for curtailment. Thus, it can be useful for regions expecting growth in renewable energy generation to understand experience across a variety of jurisdictions. In the countries examined in this paper, curtailment levels have often been $1 \%-3 \%$ of wind generation or less, but vary considerably by region. In some areas, such as China, Italy, and in the ERCOT market in the United States, curtailment levels have exceeded $10 \%$ of renewable generation in some years. In these instances, a lack of adequate transmission capacity has led to elevated curtailment levels. Subsequent investments in transmission capacity and grid infrastructure where they have occurred have helped substantially lower curtailment levels. Solar generation was not curtailed in any of the regions examined in this review, although this may become an issue in regions as higher penetrations of solar are reached.

Operational changes have also been found to be useful in addressing challenges associated with renewable energy curtailment. In particular, market-based solutions have proven useful in reducing curtailments in both the United States and Europe, but under these approaches, the curtailed energy is generally not compensated. When curtailment is not compensated, developers need to assess the risk and quantify the amount of future curtailment in order to assess project economics. However, there is uncertainty in future curtailment levels because they depend on many factors, including future markets, future penetration levels of wind and solar energy, and future flexibility in the balance of generation. Even when curtailment is compensated, developers need to assess the risk that these rules may change. Utilities with renewable energy targets also need to assess the risk and quantity of future curtailment, which is likely to increase with increased penetrations of wind and solar power. The issue of curtailment risk, and how that risk should be borne, is ripe for future research.

\section{Acknowledgments}

This article was developed by participants of the International Energy Agency Task 25 working group on Design and Operation of Power Systems with Large Amounts of Wind Power (see http://www.ieawind.org/task 25.html). The authors would like to thank Dr. Thomas Ackermann, who provided the German curtailment data, and the U.S. Department of Energy, Office of Energy Efficiency and Renewable Energy, who supported this work. E.G.L. thanks the "Ministerio de Economía y Competitividad" and European Union FEDER, which supported this work under project ENE2012-34603.

\section{References}

[1] Burke, D. J. ; O'Malley, M.J., Factors Influencing Wind Energy Curtailment, IEEE Transactions on Sustainable Energy, 2011, Vol. 2, Issue 2: 185-193.

[2] Yingzhong Gu, Le Xie, Fast Sensitivity Analysis Approach to Assessing Congestion Induced Wind CurtailmentIEEE Transactions on Power Systems, 2014, Vol. 29, Issue 1: 101-110.

[3] Kane, L. and G. Ault. A review and analysis of renewable energy curtailment schemes and Principles of Access: Transitioning towards business as usual, Energy Policy 2014 (72): 67-77.

[4] Bai, J. (2014). "Research and Practice of the Wind Power Integration in China." Prepared for IEA T25 Meeting, September 17-19, 2014. Munich, Germany: $36 \mathrm{pp}$.

[5] Wang, C. (2014). "Renewable Energy Priority Dispatch and Study on Key Problems." State Grid Energy Research Institute. Accessed April 4, 2015: http://uvig.org/wp-content/uploads/2014/06/Renewable_Energy_Priority_Dispatch_in_China.pdf.

[6] Canbing Li, Haiqing Shi Yijia Cao, Jianhui Wang, Yonghong Kuang, Yi Tan, Jing Wei, Comprehensive Review of renewable energy curtailment and avoidance: aspecific example in China, Renewable and Sustainable Energy Reviews, January 2015 (41):,1067-1079.

[7] Bundesnetzagentur. Monitoringreport 2013, Bonn, Germany; 2014. http://www.bundesnetzagentur.de/SharedDocs/Downloads /EN/BNetzA/PressSection /ReportsPublications/2013/MonitoringReport2013.pdf

[8] EirGrid; Soni. (2014). Annual Wind Constraint and Curtailment Report 2013. EirGrid. Accessed April 22, 2015: http://www.eirgrid.com/media /Annual_Wind_Constraint_and_Curtailment_Report_2013.pdf.

[9] EirGrid and SONI. (2010). "Facilitation of Renewables." EirGrid and SONI. http://www.eirgrid.com/renewables/facilitationofrenewables/.

[10] O'Sullivan, J. A. Rogers, D. Flynn, P. Smith, and M. O'Malley. Studying the maximum instantaneous non-synchronous generation in an Island system frequency stability challenges in Ireland. IEEE Trans. Power Systems, 2014, 29(6): 2943-2951.

[11] EirGrid and SONI. (2014). "Delivering a Secure Sustainable Electricity System.” EirGrid and SONI. http://www.eirgrid.com/operations/ds3/information/.

[12] EirGrid (2015): DS3 Operational Capability Outlook 2015EirGrid and SONI. (2014). "Delivering a Secure Sustainable Electricity System.” EirGrid and SONI. http://www.eirgrid.com/operations /ds3/information/.

[13] Single Electricity Market (2011) Principles of Dispatch and the Design of the Market Schedule in the Trading and Settlement Code SEM Committee Decision Paper, 26th August 2011, SEM-11-062 
[14] Estanqueiro, A.; Rygg Ardal, A.; O’Dwyer, C.; Flynn, D.; Huertas-Hernando, D.; Lew, D.; Gomez-Lazaro, E.; Ela, E.; Revuelta, J.; Kiviluoma, J.; Rodrigues, L.; Amelin, M.; Holtinen, H. (July 2012). "Energy storage for wind integration: Hydropower and other contributions." Prepared for IEEE Power and Energy Society General Meeting, July 22-26, 2012. San Diego, CA: 8 pp. http://ieeexplore.ieee.org /xpl/articleDetails.jsp?arnumber=6344652\&tag=1.

[15] Estanqueiro, A.; Mateus, C.; Pestana, R. (2010). "Operational experience of extreme wind penetrations." Prepared for $9^{\text {th }}$ International Workshop on LargeScale Integration of Wind Power into Power Systems as well as on Transmission Networks for Offshore Wind Power Plants, 2010. Quebec City, Canada: http://repositorio.lneg.pt/bitstream/10400.9/1172/1/Paper_w159_Estanqueiro.pdf.

[16] Martin-Martinez, S.; Gomez-Lazaro, E.; Molina-Garcia, A.; Vigueras-Rodriguez, A.; Milligan, M.; Muljadi, M. "Participation of wind power plants in the Spanish power system during events." Prepared for Power and Energy Society General Meeting, July 22-26, 2012. San Diego, CA: 8 pp. http://ieeexplore.ieee.org/stamp/stamp.jsp?tp=\&arnumber=6345017.

[17] Martin-Martinez, S.; Gomez-Lazaro, E.; Molina-Garcia, A.; Honrubia-Escribano, A. "Impact of wind power curtailments on the Spanish power system operation." Prepared for Power and Energy Society General Meeting, July 27-31, 2014. Washington, DC: 5 pp. http://ieeexplore.ieee.org/stamp/stamp.jsp?tp=\&arnumber=6939535.

[18] Martin-Martínez, S.; Vigueras-Rodríguez, A.; Gomez-Lazaro, E.; Molina-Garcia, A.; Muljadi, E.; Milligan, M. Advances in Wind Power. Rijeka, Croatia: Intech. 2012: 285-304. http://cdn.intechopen.com/pdfs-wm/41126.pdf.

[19] Soder, L.; Abildgaard, H.; Estanqueiro, A.; Hamon, C.; Holttinen, H.; Lannoye, E. "Experience and challenges with short-term balancing in European systems with large share of wind power." IEEE Transactions on Sustainable Energy 2012 (3:4): pp. 853-861. http://ieeexplore.ieee.org/stamp/stamp.jsp?tp=\&arnumber=6298072.

[20] Bird, L.; Cochran, J.; Wang, X. Wind and Solar Energy Curtailment: Experience and Practices in the United States. NREL/TP-6A20-60983. Golden, CO: National Renewable Energy Laboratory, March 2014. http://www.nrel.gov/docs/fy14osti/60983.pdf.

[21] Maggio, D. (June 25, 2013; March 10, 2014). Personal communication of ERCOT curtailment data.

[22] McMullen, M. "UVIG Forecasting Workshop MISO.”. Prepared for UVIG Forecasting Workshop, 2013. Salt Lake City, Utah.

[23] IEA Wind. IEA Wind 2013 Annual Report: Canada.ISBN 0-9786383-9-5, $2014 . \quad$ International Energy Agency. Accessed May 5, 2015: https://www.ieawind.org/annual_reports_PDF/2013/2013\%20AR_small_090114.pdf.

[24] “Total gross electricity generation." (2014). Eurostat. Accessed April 17, 2015: http://ec.europa.eu/eurostat/tgm/table.do?tab=table\&init=1\&language =en\&pcode=ten00087\&plugin=1.

[25] “Generation.” (2015). China Electricity Council. Accessed April 22, 2015: http://english.cec.org.cn/No.117.index.htm.

[26] “Japan: Overview.” (2015). U.S. Energy Information Administration. Accessed April 22, 2015: http://www.eia.gov/countries/cab.cfm?fips=ja.

[27] "Electricity Data Browser." (2015). U.S. Energy Information Administration. Accessed April 22, 2015: http://www.eia.gov/electricity/data/browser /\#/topic/0?agg=2,0,1\&fuel=vtvo\&geo=g\&sec=g\&linechart=ELEC.GEN.ALL-US-99.A ELEC.GEN.COW-US-99.A ELEC.GEN.NG-US99.A ELEC.GEN.NUC-US-99.A ELEC.GEN.HYC-US-99.A ELEC.GEN.WND-US-99.A\&columnchart=ELEC.GEN.ALL-US-99.A ELEC.GEN.COWUS-99.A ELEC.GEN.NG-US-99.A ELEC.GEN.NUC-US-99.A ELEC.GEN.HYC-US-99.A ELEC.GEN.WND-US-99.A\&map=ELEC.GEN.ALL-US99.A\&freq=A\&ctype=linechart\&ltype=pin\&rtype=s\&maptype=0\&rse=0\&pin=.

[28] Yu, N. P.; Sheng, H. Y.; Johnson, R. Economic Valuation of Wind Curtailment Rights. Power and Energy Society General Meeting (PES), 2013 IEEE.

[29] Dudurych, I.M., J. O'Sullivan, A. Rogers, D. Bell, S. Rourke and N. Kamaluddin. Tools for handling high amounts of wind generation in National Control Centre in Ireland. IEEE PES General Meeting, July 2012, San Diego.

[30] Henriot, A. Economic curtailment of intermittent renewable energy sources, Energy Economics, 2015 (49): 370 -379.

[31] Ela, E. Using Economics to Determine the Efficient Curtailment of Wind Energy,NREL Technical Report, NREL/TP-550-45071, February 2009.

[32] Moradzadeh, M.; Zwaenepoel, B.; Van de Vyver, L. Congestion-induced Wind Curtailment Mitigation Using Energy Storage. IEEE International Energy Conference (ENERGYCON), 2014.

[33] Jin Zou; Rahman, S.; Xu Lai. Mitigation of Wind Output Curtailment by Coordinating with Pumped Storage and Increasing Transmission Capacity, IEEE Power \& Energy Society General Meeting, 2015.

[34] Cleary, B.; Duffy, A.; O'Connor, A.; Conlon, M.; Fthenkais, V. Assessing the Economic Benefits of Compressed Air Energy Storage for Mitigating Wind Curtailment. . IEEE Transactions on Sustainable Energy, 2015, Volume 6, Issue 3: 1021 - 1028.

[35] McKenna, E.; Grunewald, P.; Thompson M. Going with the Wind: Temporal Characteristics of Potential Wind Curtailment In Ireland in 2020 and Opportunities for Demand Response. Power and Energy Society General Meeting (PES), 2013 IEEE.

[36] Ruiz, P. "Topology Control Algorithms (TCA)”. Prepared for UVIG Spring Technical Workshop by the Brattle Group, 2013. Charleston, SC.

[37] Redes Energeticas Nacionais. Capacidades Indicativas de Interligação para Fins Comerciais para o ano de 2013. Report REN RL ELPR-PR, 2012. http://www.centrodeinformacao.ren.pt/.

[38] Connolly, S.; Parks, K.; Janacek, C. Wind induced coal plant cycling costs and the implications of wind curtailment for the Public Service Company of Colorado. Final report for Xcel Energy, 2011. Denver, CO.

[39] Single Electricity Market (2013) Treatment of Curtailment in Tie-break situations - Decision Paper, 1st March 2013, SEM-13-010

[40] TWENTIES. Report on the economic impact of enhanced network flexibility and new solutions for ancillary services (Indicative title). Draft. Deliverable $15.1,2013$

[41] TWENTIES. Market impact of offshore wind power and hydro power (Indicative title). Draft. Deliverable 16.6, 2013.

[42] TWENTIES. TWENTIES project. Final report, 2013. http://www.ewea.org/fileadmin/files/library/publications/reports/Twenties_report_short.pdf. 